\title{
Phonological Development in Hearing Learners of a Sign Language: The Influence of Phonological Parameters, Sign Complexity, and Iconicity
}

\author{
Gerardo Ortega $^{\mathrm{a}, \mathrm{b}}$ and Gary Morgan ${ }^{\mathrm{c}, \mathrm{d}}$ \\ ${ }^{a}$ Radboud University, ${ }^{b}$ Max Planck Institute for Psycholinguistics, ${ }^{\circ}$ City University London, and \\ dUniversity College London
}

The present study implemented a sign-repetition task at two points in time to hearing adult learners of British Sign Language and explored how each phonological parameter, sign complexity, and iconicity affected sign production over an 11-week (22-hour) instructional period. The results show that training improves articulation accuracy and that some sign components are produced more accurately than others: Handshape was the most difficult, followed by movement, then orientation, and finally location. Iconic signs were articulated less accurately than arbitrary signs because the direct sign-referent mappings and perhaps their similarity with iconic co-speech gestures prevented learners from focusing on the exact phonological structure of the sign. This study shows that multiple phonological features pose greater demand on the production of the parameters of signs and that iconicity interferes in the exact articulation of their constituents.

Keywords sign language; L2 acquisition; phonology; iconicity; British Sign Language (BSL)

\footnotetext{
This research was supported by the Mexican National Council of Science and Technology Grant 304770 and the Economic and Social Research Council of Great Britain to the ESRC Deafness, Cognition and Language Research Centre under Grant 620-28-600. This manuscript was completed while the first author worked as a postdoctoral fellow at the Centre for Language Studies at Radboud University and the Max Planck Institute for Psycholinguistics with an ERC Starting Grant awarded to Aslı Özyürek. We would like to express our gratitude to the students at York St. John University for their collaboration in the study and to Ann Gregory, Penny Howarth, Amanda Smith, Claire Ward, and Chris Hall for their invaluable assistance in the data collection. We would also like to thank Alex Lau Zhu and Taffany Leung who assisted in the data collection. We are indebted to the anonymous reviewers whose insightful comments improved the final version of this manuscript. The videos employed in this study were developed by Vinson, Cormier, Denmark, Schembri, and Vigliocco (2008) and are publicly available on IRIS (http://www.iris-database.org/).

Correspondence concerning this article should be addressed to Gerardo Ortega, Center for Language Studies Radboud University Nijmegen and Max Planck Institute for Psycholinguistics, Wundtlaan 1, Kamer 304, Nijmegen, The Netherlands 6525XD. E-mail: gerardo.ortega@mpi.nl
} 


\section{Introduction}

There is a general consensus that, in spoken languages, learners' first language (L1) is probably the most important factor influencing the acquisition of the sounds of a second language (L2; Best \& Tyler, 2007; Flege, 1995; Iverson \& Evans, 2007; Suter, 1976). An intriguing question for the field of L2 research is how phonological acquisition occurs when the new target language is expressed in a different modality, for example, when the L1 is a spoken language but the L2 is a signed language. There is some research showing that proficient hearing signers use sign phonological information during lexical access (Shook \& Marian, 2012) in a similar way to deaf L1 signers (Morford, Wilkinson, Villwock, Piñar, \& Kroll, 2011). However, the factors involved in sign L2 phonological development remain widely unexplored. Given that sign phonological representations share many properties with the phonologies of spoken languages (Brentari, 1999; Sandler \& Lillo-Martin, 2006), it may be the case that some aspects of L2 phonological development could also occur in sign L2 learning. One such modality-independent property might be that phonologically complex structures in sign will pose greater articulatory demands than simpler ones and as a result will be mastered at later stages. On the other hand, the differences in how spoken and signed languages are perceived and expressed may exhibit some modality-specific differences in L2 learning. This might be the case of iconicity, which is a pervasive feature of all sign languages. It is relatively uncommon that spoken words reflect in their phonological structure perceptual aspects of the concept they represent (as in onomatopoeia). In contrast, the visual modality is biased in that signs often represent in their linguistic structure the physical features of their referent (Klima \& Bellugi, 1979; Perniss, Thompson, \& Vigliocco, 2010; Taub, 2001). It has been shown that iconicity has a facilitative effect in sign L2 learning at the lexical level (Baus, Carreiras, \& Emmorey, 2012; Campbell, Martin, \& White, 1992; Lieberth \& Gamble, 1991) but it has not been explored how iconicity may influence the development of a visual L2 phonology. In addition, hearing nonsigners employ a rich gestural system in conjunction with their speech so it may be possible that their experience with manual communication could also affect sign articulation. The aim of the present study was to investigate how each phonological parameter, signs' phonological complexity, and their degree of iconicity affect articulation in hearing learners of British Sign Language (BSL). This study also investigate whether any phonological development can be discerned when comparing participants' performance before and after an 11-week period comprising 22 hours of training at the beginning level of BSL. 


\section{Acquisition of Phonology in a Signed L2}

In spoken languages, the development of an L2 phonological system involves setting up novel sound representations not present in the native language. These new sounds are acquired through learners' ability to perceive phonological contrasts among different sounds (Escudero \& Boersma, 2004). The capacity to segment and accurately discriminate the sounds in the acoustic input is therefore crucial for L2 phonological development. Indeed, learners often fail to discriminate target sounds because they tend to assimilate them to the most similar element in their L1 phonological repertoire (Best \& Tyler, 2007; Piske, MacKay, \& Flege, 2001) and this happens across many L1-L2 language pairs. The inability to perceive phonological contrasts thus influences speech production (Flege, 1992, 1995). This finding raises the question of what happens when there are cross-linguistic modality differences (i.e., when the L1 is a spoken language and the L2 is a signed language). It remains an empirical question as to what factors explain the errors of sign language learners when the L1 cannot exert influence on the L2.

In languages expressed in the manual-visual modality, the structure of a sign is determined by three main factors: the internal constituents (phonological parameters), the number of contrastive features (phonological complexity), and the visual resemblance to its referent (iconicity). Potentially, each one of these contributes differently to accurate sign articulation. Why these might be relevant is explained in the following sections.

\section{Phonological Parameters of Signs: Handshape, Location, Movement, and Orientation}

In the same way that individual phonemes combine to make up words, signs consist of a set of manual components (the handshape, location, movement, and hand orientation) that when combined produce meaningful manual forms ${ }^{1}$ (Battison, 1978; Brentari, 1999; Stokoe, 1960; van der Kooij, 2002). The parameters consist of a finite number of handshapes, locations, movements, and orientations and, in order to develop a visual phonological system, learners must develop the permissible categories for these parameters.

Studies on sign L1 acquisition have shown that young children exposed to a signed language from early infancy master each of these components at different stages with location being first to be mastered, followed by movement, and finally handshape (Conlin, Mirus, Mauk, \& Meier, 2000; Marentette \& Mayberry, 2000; Morgan, Barrett-Jones, \& Stoneham, 2007). Boyes-Braem (1990) argued that articulatory difficulty, perceptual saliency, and frequency 
in the input predicted the order of acquisition of parameters. There is limited evidence on whether adult sign L2 learners also master the parameters of signs at different stages and, if so, whether their pattern of acquisition contrasts significantly from that observed in young children.

Some of the articulation errors in hearing learners have been attributed to the complexity of a mastering novel motor task. When asked to imitate signs from a foreign sign language, hearing adults with no prior expertise with a spatial-visual language produced the proximalised movements that characterise L1 phonological development, that is, articulating the sign with joints closer to the torso instead of the distal ones. Deaf signers, in contrast, were less likely to proximalise movement because of their experience with their own sign language (Mirus, Rathmann, \& Meier, 2001). Because proximalization errors are observed in both deaf children and hearing adults learning a sign language, it has been argued that these articulation errors reflect the complexity of learning a novel motoric task.

Other accounts concur that articulation errors in sign L2 learners relate in part to their inexperience using the body as linguistic articulators but also suggest that perception may play a role. The Cognitive Phonology Model (CPM) proposes that, at the early stages of sign learning, hearing adults produce articulation errors because they have not yet developed adequate signing skills and because they have problems perceiving the sign components (Rosen, 2004). The CPM proposes that, for example, substitution, additions, and deletions of sign segments can be regarded as dexterity errors, while mirrorization and parallelization are more likely to be the result of inaccurate sign perception.

Bochner, Christie, Hauser, and Searls (2011) investigated nonsigners' ability to perceive the phonological parameters of signs. After testing beginner, intermediate hearing learners, and deaf native signers in a sign discrimination task, they found that native signers were the most accurate, followed by intermediate signers, and finally beginners, suggesting that experience and age of exposure significantly enhances phonological discrimination supporting the CPM (Rosen, 2004). The study also reported that the parameter most difficult to discriminate for a nonsigner was movement; location was the easiest, and handshape and orientation fell between these two parameters. It is yet to be investigated whether articulation accuracy also differs across sign parameters in sign L2 learners and how their errors pattern with phonological discrimination.

\section{Phonological Complexity}

Apart from specific phonological parameters, the overall structure of a sign also contributes to its phonological complexity. Battison (1978) noted that signs 
have systematic organisation and that only certain combinations of handshapes, locations, and movements are permissible and depended on whether a sign is produced with one or two hands. He stipulated that, from an articulatory perspective, two-handed signs are more complex than one-handed signs and that signs in which the hands act independently require greater articulatory dexterity than signs with symmetrical movement. Based on these observations, the Dominance and Symmetry constraints (Battison, 1978) establish four types of signs:

1. Type 0 signs are one-handed signs.

2. Type 1 signs are two-handed signs with the same handshape, producing a symmetrical (synchronised or alternating) movement.

3. Type 2 signs are also two-handed signs both with the same handshape but the dominant hand acting on the nondominant (i.e., both hands move independently from each other).

4. Type 3 signs are two-handed signs with the dominant hand acting on the nondominant hand and both presenting different handshapes.

This systematic organization of signs has been attested in many unrelated sign languages (Eccarius \& Brentari, 2007) and has been attributed to the pressure posed by signers' perceptual systems for processing manual signals (Battison, 1978; Johnston \& Schembri, 2007). Battison (1978) argued, for instance, that many signs articulated in neutral signing space often consist of two hands because of the restrictions of the perceptual system. In other words, peripheral vision has limited acuity compared to central vision hence it requires more visual information to process signs efficiently. The different sign types established by the Dominance and Symmetry constraints are therefore a good framework with which to operationalise sign phonological complexity. Onehanded signs are phonologically simpler than two-handed signs because the latter have twice as many phonological features to discriminate and articulate (i.e., two sets of handshapes, locations, movements, and orientations). It can be predicted that sign L2 learners will experience greater difficulty articulating signs with multiple components. This claim, however, has not been controlled in experimental settings up to now and thus the impact of sign structure (Battison's constraints) on sign L2 language acquisition remains to be explored.

\section{Iconicity}

The third factor that determines sign structure is iconicity. Through iconic depictions, signs can represent physical features of a referent, their spatial relationship with other objects, and motion patterns of different entities (Klima 
\& Bellugi, 1979; Perniss et al., 2010; Taub, 2001). For instance, the BSL sign CORKSCREW $^{2}$ represents the opening of a bottle with a corkscrew and thus exhibits an iconic form-referent relationship. This link is more direct than for the arbitrary BSL sign SISTER, which is articulated by tapping a bent index finger on the nose, and as such does not exhibit any relationship between the linguistic form and the concept it represents. Iconicity can be expressed in a lexical unit as a whole (Mandel, 1977) or it can be expressed in one or more of the signs' phonological constituents (Cuxac, 1999; van der Kooij, 2002). Access to sign iconicity is influenced by the viewer's age, shared world knowledge (Griffith, Robinson, \& Panagos, 1981), and cultural background (Pizzuto \& Volterra, 2000). Thus it is not always easy to determine the referent that motivates a linguistic form. For this reason, Klima and Bellugi (1979) have argued that iconicity lies along a continuum with some iconic signs showing clearer form-meaning links than others.

The role of iconicity has been an important focus of attention in L1 and L2 sign acquisition. Developmental studies report that iconicity does not facilitate sign L1 acquisition because young deaf children lack the necessary world knowledge to make associations between an iconic sign and its referent (Meier, Mauk, Cheek, \& Moreland, 2008; Newport \& Meier, 1985; Orlansky \& Bonvillian, 1984; but see Ortega, Sümer, \& Özyürek, 2014, and Thompson, Vinson, Woll, \& Vigliocco, 2013, for more nuanced claims). In contrast, direct sign-referent mappings have been shown to have a positive effect on sign L2 acquisition by adults. Hearing nonsigners are significantly better at recalling, naming, and translating iconic signs compared with arbitrary ones (Baus et al., 2012; Campbell et al., 1992; Lieberth \& Gamble, 1991). This effect has been attributed to iconicity strengthening the link between a motivated linguistic form and its conceptual representations (Baus et al., 2012). The different effects of iconicity on L1 and L2 sign acquisition indicate that hearing adults have the conceptual knowledge and the cognitive skills to map an iconic sign with its referent, which in turn facilitates sign learning. However, studies in hearing adults have not focused on how iconicity affects sign articulation and so its effects on L2 phonological development remain uninvestigated.

An important reason to include iconicity as a factor that may shape sign L2 development is that it is a common feature shared with many of the co-speech gestures used by the speaking community. Gestures are a fundamental aspect of human communication present in all ages and cultures (Kendon, 2004). Much evidence suggests that speech and gestures are not independent but rather are complex, highly integrated systems that convey important information in a multimodal utterance (Kelly, Özyürek, \& Maris, 2010; Özyürek, Willems, Kita, 
\& Hagoort, 2007). For example, when speakers produce the gesture of smoking while saying "I'm going outside" they are using an iconic manual depiction to express information not encoded in their speech. Iconic gestures may involve reenactment of an action (e.g., mimicking the action of smoking) or they can represent physical characteristics of objects (e.g., tracing the cylindrical shape of a bottle). Another type of gesture commonly used by speakers are emblems whose structures are not iconically motivated but have specific forms and pragmatic conventions of use within a culture (Kendon, 1995), for example, the emblem to mean "all good."

One of the reasons why nonsigners understand the meaning of many signs may be that they share many similarities with their co-speech gestures. For instance, the BSL sign HOPE overlaps in form and meaning with the emblem A A critical distinction, however, is that gestures are holistic units that cannot be decomposed into sublexical constituents - in other words, they lack the property of phonology. Nonetheless, even when L2 learners lack a manual phonological system, they may still understand the meaning of many signs because of their iconic features or because they resemble their own co-speech gestures. The similarities between some signs and learners' gestures could therefore have an impact on their sign L2 phonological development.

In summary, sign structure is determined by three main factors: the components that constitute signs (handshape, location, movement, and orientation), how these are organised (the Dominance and Symmetry constraints), and signs' resemblance to their referent (iconicity) which is a characteristic also shared with many co-speech gestures. The aim of this study was to investigate how each of these factors affects the production of the parameters of signs in early sign L2 learners.

\section{The Present Study}

We evaluated articulation errors in a sign repetition task by hearing adults learning BSL. In the spoken modality, the nonword repetition task involves discrimination of the acoustic input, assembly of the phonemes into a lexical entry, and articulation of the word (Coady \& Evans, 2008). By comparing participants' output with the target it is possible to establish what phonological features cause more difficulties in production (e.g., vowel length or marked phonological features). This technique has been adapted for sign languages to study phonological development in typically developing signing children (Mann, Marshall, Mason, \& Morgan, 2010) and children with specific language impairments in sign (Mason et al., 2010). 
As has been shown in L2 acquisition of spoken languages (Escudero \& Boersma, 2004), sign L2 phonological development also requires accurate discrimination of the contrastive features of the target language. Based on evidence that sign phonological discrimination is more difficult for some parameters than others (Bochner et al., 2011), the first prediction is that sign L2 learners will articulate the sign parameters significantly differently from each other, with different parameters exhibiting systematically different levels of accuracy. That is, the components that constitute signs (handshape, location, movement, and orientation) are predicted to be a source of differential developmental difficulty. If accurate discrimination is the only factor responsible for accurate sign production, it is expected that location will be the easiest to articulate, movement the most difficult, and handshape and orientation will fall between these two parameters. This is the same pattern of errors observed in phonological discrimination (Bochner et al., 2011). A different pattern of errors would suggest that perception alone does not explain errors in hearing adults.

Because complex signs have a larger number of features and thus pose greater articulatory demands than simple signs (Battison, 1978), the second prediction is that, as the number of phonological components of a sign increases, the repetition accuracy will decrease accordingly. In other words, this prediction pertains to sign organisation and number of contrastive features (the Dominance and Symmetry constraints) that make phonological complexity a source of developmental difficulty.

Given that the meaning of some iconic signs is accessible to hearing nonsigners (Klima \& Bellugi, 1979; Pizzuto \& Volterra, 2000) and because these direct links facilitate learning (Baus et al., 2012; Campbell et al., 1992; Lieberth \& Gamble, 1991), possibly via their similarities with co-speech gestures, it is predicted that iconicity will have a positive effect in sign articulation. Alternatively, however, familiarity with iconic or gesture-like signs may have a negative effect in sign production because learners might focus on the meaning of the signs and not the sign's exact phonological constituents.

Finally, we expect instruction to have a positive effect on participants' ability to discriminate and execute the phonological parameters of signs. Based on research showing that learners develop sensitivity to an L2 phonology after only 14 hours of instruction (Osterhout \& McLaughlin, 2006), we predict that participants will show significant improvement in sign articulation at the second testing session. However, it is also possible that the processing of visual input (as opposed to speech) may hinder signed phonological development and thus participants may require more exposure to a sign language to improve over time. 


\section{Method}

\section{Participants}

Fifteen hearing undergraduate students at York St. John's University took part in a sign repetition task. Participants were enrolled in an 11-week course of BSL for beginners that consisted of two 1-hour lessons per week. After 11 weeks (22 hours of instruction), participants completed the first of three modules to achieve the BSL level 1 as accredited by Signature, the most recognised awarding body of BSL certifications in the United Kingdom (http://www.signature.org.uk/british-sign-language). Participants were native speakers of English and all resided in the United Kingdom from birth. None had knowledge of any sign language at the outset of the study but five reported basic knowledge of the BSL manual alphabet. This was not a concern given that initialised signs are rare in BSL (it has a two-handed alphabet). All participants had good or corrected vision and two participants reported being left-handed. Six participants failed to return to the second testing session so their data were excluded from the analysis. The final cohort of participants consisted of nine BSL students ( 8 female, mean age $=20.22$ years).

\section{Stimuli}

The stimuli consisted of video clips of individual BSL signs from a norming study that collected ratings by deaf signers of familiarity, age of acquisition, and iconicity for $300 \mathrm{BSL}$ signs. These videos were originally developed by Vinson, Cormier, Denmark, Schembri, and Vigliocco (2008). Pooling from this resource, signs were selected so that the types of movements, handshapes, and locations were balanced across conditions. Because of the limited literature on orientation and its marked features, this parameter could not be balanced. For movement, the stimuli were selected so that signs in both conditions had an equal number of path movement (transitions of the hands within neutral signing space), internal movements (movements of the wrist and/or fingers), or signs including both movement types. With regard to handshape, the stimuli were selected so that arbitrary and iconic signs included approximately the same number of marked and unmarked handshapes. Sutton-Spence and Woll (1999) proposed that the unmarked handshapes for BSL are: (open hand with extended and adducted fingers), 解 (open hand with extended abducted fingers), (pointing index), and (closed fist). In addition, because there are some signs that involve transition from one handshape to another, the stimuli were also selected so that both conditions had a balanced number of signs with handshape change. There is no evidence showing that one type of handshape 
change is more complex than another (e.g., close to open vs. open to close) so no attempt was made to balance for type of handshape change. Finally, the place of articulations of all signs was also balanced so that signs across conditions were articulated in the same locations.

We used the Dominance and Symmetry constraints (Battison, 1978) to operationalise sign phonological complexity. From an articulatory perspective (Battison, 1978), we considered one-handed signs as phonologically simpler than two-handed signs because the latter have two sets of handshapes, locations, movements, and orientations. In addition, we considered that body-anchored signs are more complex than signs in neutral space given that signs articulated in neutral signing space lack a specification for the parameter location (van der Kooij, 2002) and therefore learners would have one feature less to discriminate.

The four sign types defined in the Dominance and Symmetry constraints were adapted to create six subcategories of increasing phonological complexity. In addition to the four sign types (henceforth, Complexity Levels), two additional categories distinguishing between signing space and the body as location were included. By adding two additional Levels to Battison's sign types (signs with and without body contact) the classification of the stimuli resulted in a total of six subcategories of increasing phonological complexity (see Figure 1). Level 1 signs were one-handed signs produced in signing space (e.g., EUROPE) and Level 2 signs consisted of one-handed signs making contact with the body (e.g., SISTER). The commonality between these two Complexity Levels is that signs include movement of the dominant hand only but differ in their place of articulation (signing space and the body, respectively). The next two Complexity Levels involve both hands in which the nondominant hand is a mirror image of the dominant hand. Both hands execute the same movement and use the same handshape. The difference being the place of articulation: Level 3 signs were symmetrical two-handed signs in signing space (e.g., HOSPITAL) and Level 4 signs were symmetrical two-handed signs with contact with the body (e.g., RELAX). Levels 5 and 6 signs were also two-handed signs where the dominant hand acted independently from the nondominant hand. In both cases, the dominant hand acts upon the nondominant hand but in Level 5 signs both articulators used the same handshape (e.g., CORKSCREW), while Level 6 signs presented different handshapes (e.g., THEATRE). Importantly, the nondominant hand always has an unmarked hand configuration and the dominant hand can adopt any hand configuration. In this classification, one-handed signs in neutral space were the most phonologically simple (Level 1) while two-handed signs with asymmetrical movement were the most complex signs 

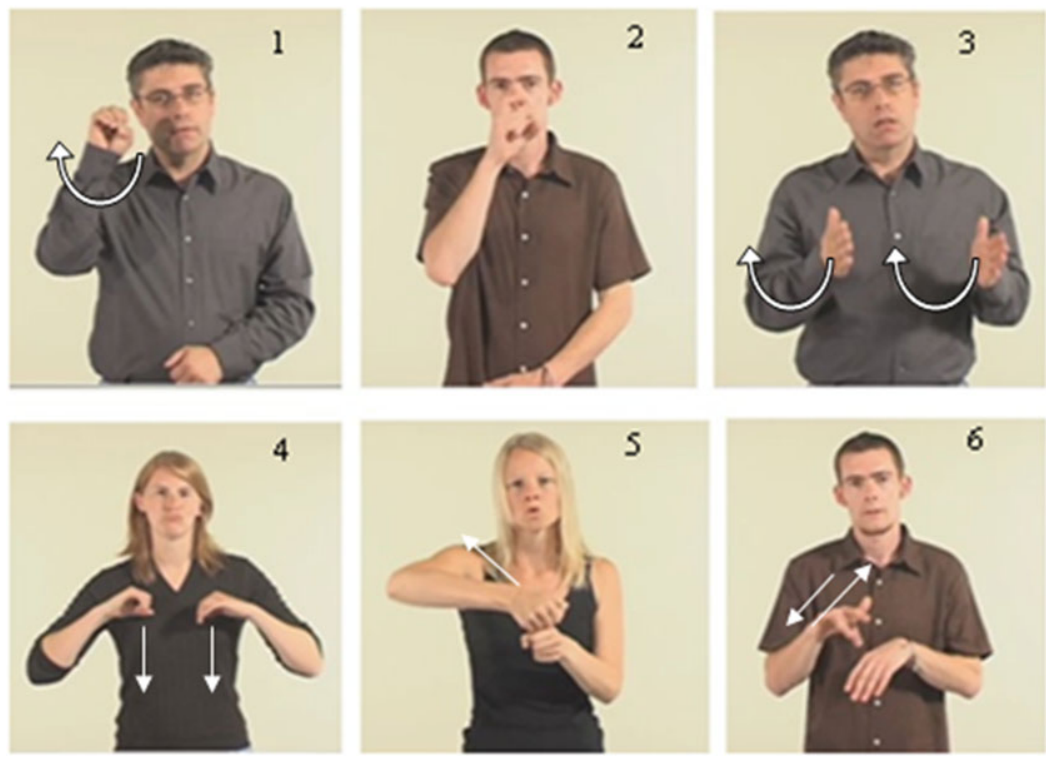

Figure 1 BSL signs exemplifying the subcategories of progressively more difficult articulatory complexity. (1) EUROPE, one-handed sign with no contact with the body; (2) SISTER, one-handed sign with contact with the body; (3) HOSPITAL, two-handed sign with symmetrical movement in neutral space; (4) RELAX, two-handed sign with contact with the body and symmetrical movement; (5) CORKSCREW, two-handed signs with asymmetrical movement and nondominant hand as place of articulation; (6) THEATRE, two-handed sign with asymmetrical movement and handshape, and dominant hand acting on the nondominant Still images adapted from videos from (Vinson et al., 2008).

(Level 6). The rest of the Complexity Levels gradually increase in phonological complexity as the number of contrastive features increase.

We defined iconic signs as those whose forms are motivated by the form of their referent. Given that access to signs' iconic link greatly depends on age, world knowledge, and cultural background (Griffith et al., 1981; Pizzuto \& Volterra, 2000), we operationalised iconicity through ratings from a group of 15 hearing nonsigners using the same 7-point Likert scale as Vinson et al. (2008) where 1 represented highly arbitrary signs and 7 highly iconic ones. None of these participants took part in the actual experiment. This measure is not sensitive to individual interpretations of iconicity but rather represents a numeric value within a scale showing the extent to which hearing nonsigners comprehend iconicity in the stimulus materials. The scores from the hearing 
nonsigners and those reported for deaf signers (Vinson et al., 2008) were rank ordered and compared using a Pearson correlation. We found a statistically significant correlation between the ratings given by both groups $(r=.799$, $p<0.001$ ) showing that, to a large extent, deaf signers and hearing nonsigners interpreted iconicity in a very similar way, at least for this set of signs. Nevertheless, because deaf and hearing participants might have different linguistic experiences and mental representations, the selection of stimuli was based on the ratings given by the hearing adults. As has been done in previous psycholinguistic studies (Thompson, Vinson, \& Vigliocco, 2009) we used a 3.5 cutoff point to distinguish iconic from arbitrary signs (signs above the 3.5 threshold were categorised as iconic).

In total, each condition (i.e., arbitrary and iconic signs) consisted of six subcategories with eight signs each, resulting in a total of 96 signs ( 2 conditions $\times 6$ Complexity Levels $\times 8$ signs in each Level). This distribution ensured that each condition contained overall the same number of phonological parameters (see Appendix S1 and S2 in the Supporting Information online for a description of the phonological properties of the stimuli).

\section{Procedure}

Participants were tested individually in a quiet room on a laptop twice: before they started the first module of BSL level 1 and then again after they completed the course 11 weeks later ( 22 hours of instruction). The signed stimuli were the same items in both testing sessions and were presented in different randomised orders.

A digital camera was located 1.5 meters away at a 45 degree angle from the participant to record all sign repetitions. The camera was located on the right side of right-handed participants and on the left of left-handed participants to prevent the nondominant hand blocking the dominant hand during execution of Level 5 and 6 signs. Participants were requested to watch a series of signs and to imitate them as accurately as possible. At the beginning of each trial, a fixation point appeared in the middle of the screen for 1000 milliseconds. Then the video clip of a BSL sign was shown for all of its duration (approximately 4 seconds). When the video clip had stopped and disappeared from the screen, participants were allowed up to 5 seconds to imitate the sign as accurately as possible. This way, participants executed the signs from memory and did not have the opportunity to self-correct while the sign was still on the screen. Participants ran a practice trial with 10 signs before taking part in the actual experiment. These signs were not included as experimental items. 


\section{Coding and Reliability}

After data collection, the videos of each participant's articulations were entered into the linguistic annotator program ELAN (Lausberg \& Sloetjes, 2009) and each sign was glossed with its closest English translation. In order to determine articulation accuracy, participants' renditions were coded for handshape, location, movement, and orientation. If the phonological parameter was exactly the same as the model, it was assigned a score of 1 and if it was different, it was assigned a score of 0 . Two researchers coded independently all participants' articulations adhering to the following protocol:

1. Handshape. The structure of a handshape is defined by a set of selected fingers with a specific aperture (Brentari, 1999; van der Kooij, 2002). Participants' handshapes were coded as correct only if they recruited the exact fingers with the correct configurations.

2. Movement. The use of joints proximal to the torso are common errors in nonsigners (Mirus et al., 2001). Therefore, movement was coded as correct only if participants recruited the exact joints as the stimuli during the execution of the sign.

3. Location. This parameter could take place in signing space or in a specific body part. Signs in the stimuli were always articulated in front of the model so renditions articulated on the ipsilateral or contraipsilateral side of participants were regarded as errors. For body-anchored signs, renditions deviating \pm 2 centimeters from the target were coded as errors. This distance was the most fine-grained we could achieve from the video recordings.

4. Orientation. This is the most understudied parameter in terms of phonological characteristics. We decided that renditions deviating 45 degrees or more from the target were coded as errors. This angle was set up because it was the most stringent resolution we could achieve from the angle of the video recordings.

Articulatory accuracy for each sign was calculated through the added values of each phonological parameter, in which 4 was the highest achievable score and 0 the lowest (e.g., if a participant accurately produced two parameters but misarticulated the other two, the overall score of the sign was 2 ). The same procedure and coding scheme was followed in both testing sessions. If participants produced signs that deviated from the model but were possible phonetic variations during naturalistic conversation, these were still coded as erroneous renditions. Two researchers coded the whole data set independently and reached $85 \%$ of agreement in their coding. Disagreements were discussed and resolved until 100\% agreement was reached. 


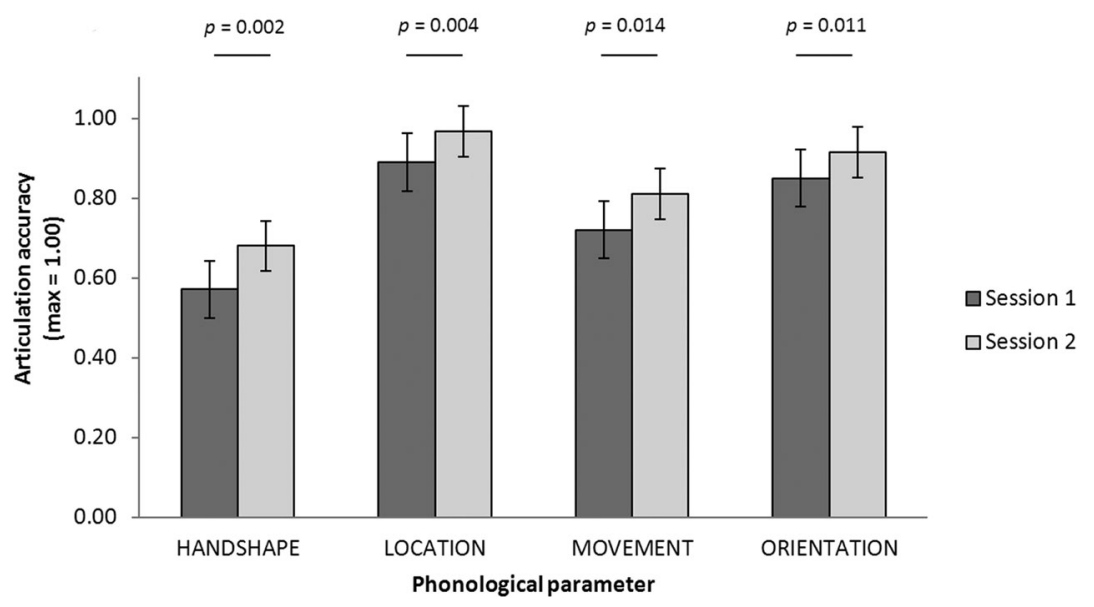

Figure 2 Articulation accuracy per phonological parameter and testing session (bars represent standard error).

\section{Results}

A 4 (phonological parameter) $\times 2$ (testing session) analysis of variance (ANOVA) was carried out to detect differences in articulation accuracy in each sign component in the two testing sessions. There was a main effect of parameter, $F(3,24)=20.66, p<0.001, \eta^{2}=.72$. Location was the most accurately articulated $(M=.93, S D=.06)$, followed by orientation $(M=$ $.88, S D=.63)$, then movement $(M=.76, S D=.09)$, and finally handshape $(M=.63, S D=.10)$. Post hoc comparisons after Bonferroni corrections revealed that all parameters were articulated significantly differently from each other (see Figure 2). Handshape was articulated significantly less accurately than location, $t(17)=18.14, p<.001, r=.72$, movement, $t(17)=9.51$, $p<.001, r=.59$, and orientation, $t(17)=15.10, p<.001, r=.69$. Location was produced significantly more accurately than movement, $t(17)=12.17, p$ $<.001, r=.65$, and orientation, $t(17)=5.64, p<.001, r=.50$. Finally, orientation was articulated significantly better than movement, $t(17)=9.91$, $p<.001, r=.37$.

There was a main effect of testing session, $F(1,8)=236.33, p<.001, \eta^{2}=$ .97 , with participants showing a significantly better performance in the second session $(M=.91, S D=.01)$ than in the first session $(M=.70, S D=.02)$. There was a significant interaction between phonological parameter and testing session, $F(3,24)=38.28, p<.001, \eta^{2}=.83$. Post hoc comparisons after 
Table 1 Mean proportion of articulation accuracies for each phonological parameter (standard deviations in brackets). The effect of instruction was calculated by subtracting accuracy in Session 2 - accuracy in Session 1

\begin{tabular}{lccc}
\hline & \multicolumn{3}{c}{ Mean articulation accuracy } \\
\cline { 2 - 4 } & Session 1 & Session 2 & Effect of BSL training \\
\hline Handshape & $0.57(0.09)$ & $0.68(0.09)$ & 0.11 \\
Location & $0.89(0.07)$ & $0.97(0.03)$ & 0.08 \\
Movement & $0.72(0.10)$ & $0.81(0.03)$ & 0.09 \\
Orientation & $0.85(0.07)$ & $0.91(0.04)$ & 0.07 \\
\hline
\end{tabular}

Bonferroni corrections between each phonological parameter across testing session were also carried out (e.g., handshape accuracy in session 1 with handshape in session 2 and so on). All the parameters were articulated significantly better in the second than in the first testing session: handshape, $t(8)=4.44, p=.002$, $r=.60$, location, $t(8)=4.05, p=.004, r=.58$, movement, $t(8)=3.14, p=$ $.014, r=.53$, and orientation, $t(8)=3.31, p=.011, r=.29$. When we looked at the effect of training in articulation accuracy for each individual parameter (i.e., what parameter showed more improvement after 11 weeks of BSL training), we observed that handshape had the strongest effect, followed by movement, then location, and finally orientation (see Table 1).

A 6 (Complexity Level) $\times 2$ (iconic vs. arbitrary) repeated-measure ANOVA was carried out to explore the impact of signs' phonological complexity and iconicity during articulation. The analysis revealed that there was a main effect of Complexity Level, $F(5,80)=9.78, p<.001, \eta^{2}=.38$, with the overall articulation accuracy being the lowest for the signs of highest phonological complexity: Level $1: M=.84, S D=.01$, Level $2: M=.86$, $S D=.01$, Level 3: $M=.79, S D=.02$, Level 4: $M=.83, S D=.01$, Level 5: $M=.82, S D=.01$, and Level $6: M=.79, S D=.02$. The negative value of the slope of the corresponding trendline across all Complexity Levels shows that articulation accuracy gradually dropped as the number of phonological features in a sign increased (slope $=-.01, R^{2}=.71$ ). Post hoc comparisons after Bonferroni corrections between the different Complexity Levels were carried out. For purpose of readability, only the relevant comparisons are reported here; $t$ and $p$ values of all possible comparisons are listed in Appendix S3 of the Supporting Information online. Of interest for this analysis were two sets of contrasts. Based on the claim that signs articulated in signing space have no 


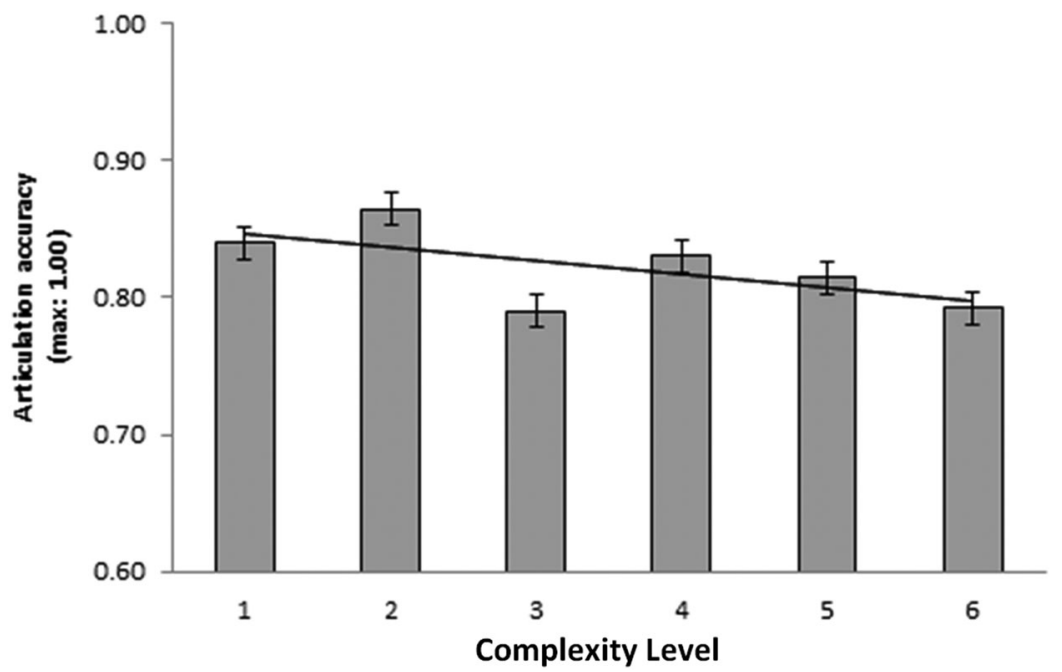

Figure 3 Articulation accuracy per Complexity Level (bars represent standard error). The corresponding trendline is displayed above the dataset ( slope $=-0.011, R^{2}=0.710$ ).

specification for location (van der Kooij, 2002) and therefore are simpler than body- anchored signs, planned comparisons between signs with and without body contact were carried out. The analysis revealed that one-handed signs in signing space (Level 1) were articulated significantly less accurately than onehanded signs with contact with the body (Level 2), $t(35)=2.07, p=.046, r=$ .24. Two-handed signs in signing space (Level 3 ) were articulated significantly less accurately that two-handed signs with contact with the body (Level 4), $t(35)=2.53, p=.016, r=.26$.

Accuracy was also compared between signs involving one and two hands. Two-handed signs in signing space (Level 3 ) were articulated less accurately than one-handed signs in signing space (Level 1), $t(35)=2.71, p=.01, r=$ .27. Similarly, one-handed signs with contact with the body (Level 2) were more accurate than two-handed signs with contact with the body (Level 4), $t(35)=2.40, p=.022, r=.25$. Accuracy in two-handed signs with independent movement with the same (Level 5) and different handshapes (Level 6) was not significantly different, $t(35)=1.56, p=.129, r=.21$, as shown in Figure 3 .

There was also a main effect of iconicity, $F(1,16)=11.92, p=.003$, $\eta^{2}=.43$, with iconic signs $(M=.81, S D=.01)$ being articulated less accurately than arbitrary signs $(M=.84, S D=.01)$. The interaction between Complexity Level and iconicity was significant, $F(5,80)$ 


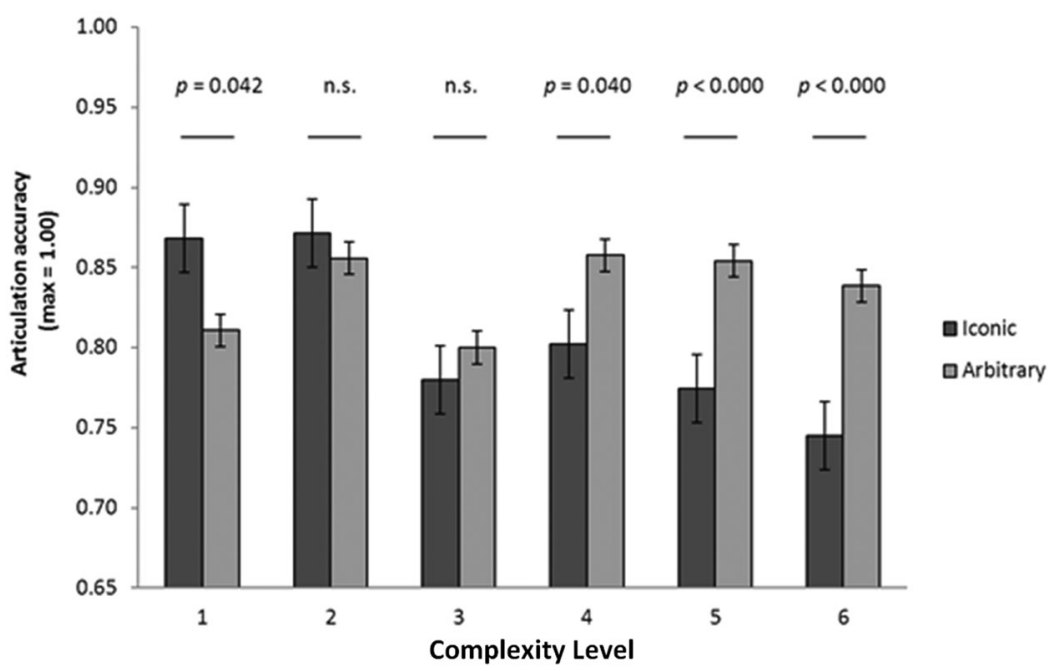

Figure 4 Articulation accuracy for iconic and arbitrary signs for each Complexity Level (bars represent standard error).

$=7.38, p<.001, \eta^{2}=.32$ (see Figure 4). Post hoc comparisons between iconic and arbitrary signs for each Complexity Level were carried out. The analysis revealed that iconic signs in Level $1\left(M_{\text {iconic }}=.87\right.$, $S D=.06)$ were articulated more accurately than arbitrary signs $\left(M_{\text {arbitrary }}=\right.$ $.81, S D=.08 ; t(17)=2.20, p=.042, r=.34)$. There was no significant difference in articulation between iconic $\left(M_{\text {iconic }}=.87, S D=.05\right)$ and arbitrary signs $\left(M_{\text {arbitrary }}=.86, S D=.05 ; t(17)=1.26, p=.224, r=.26\right)$ in Level 2. Similarly, there was no significant difference in articulation between iconic $\left(M_{\text {iconic }}=.78, S D=.11\right)$ and arbitrary signs $\left(M_{\text {arbitrary }}=.80, S D=.07 ; t(17)\right.$ $=-.95, p=.357, r=.23)$ in Level 3. Level 4 showed a significant difference, with iconic signs $\left(M_{\text {iconic }}=.80, S D=.08\right)$ being articulated less accurately that arbitrary signs $\left(M_{\text {arbitrary }}=.86, S D=.07 ; t(17)=-2.23, p=.04, r=.34\right)$. Level 5 also displayed significant differences, with iconic signs $\left(M_{\text {iconic }}=.77, S D=\right.$ $.08)$ being articulated less accurately than arbitrary signs $\left(M_{\text {arbitrary }}=.86, S D=\right.$ $.06 ; t(17)=-4.51, p<0.001, r=.46)$. Level 6 revealed a similar pattern given that iconic signs $\left(M_{\text {iconic }}=.75, S D=.09\right)$ were articulated less accurately than arbitrary signs $\left(M_{\text {arbitrary }}=.84, S D=.84 ; t(17)=-4.54, p<0.001, r=.46\right)$.

Interestingly, the data show that iconic and arbitrary signs followed different patterns of articulation accuracy as the number of phonological constituents increased (see Figure 4). Iconic signs had the highest accuracy in one-handed 
signs (Levels 1 and 2) and gradually decreased until reaching the lowest point in Level 6 signs. In contrast, arbitrary signs reached the lowest articulation accuracy in one- and two-handed signs in neutral signing space while the articulation accuracy for the rest of the sign types had approximately the same value.

\section{Discussion}

The present study investigated the emergence of a signed phonological system by hearing L2 learners of BSL. Specifically, we investigated how each phonological parameter, sign complexity, and iconicity influenced sign articulation at the earliest stages of sign language acquisition. The results of a sign repetition task revealed that at two points in time accuracy levels were highest for the parameter location, followed by orientation, then movement, and finally handshape. Accuracy significantly improved with time and, as predicted for sign complexity, articulation accuracy decreased gradually as the number of phonological components of a sign increased. Against our initial prediction, we found that iconicity had a negative effect during sign repetition as iconic signs were articulated significantly less accurately than arbitrary signs despite both sets of signs being balanced for phonological complexity.

The first prediction was that articulation accuracy in the sign repetition task would be significantly different for each sign parameter. At both points in time, location was the parameter most accurately articulated, followed by orientation, then movement, and finally handshape. In L1 development, articulation errors have been explained by children's immature motor systems (Conlin et al., 2000), different proprioceptive feedback received from each parameter (Morgan et al., 2007), and children's limited representation of their own bodies (Marentette \& Mayberry, 2000). Given that adults have fewer of these limitations, adult errors may be linked more to difficulties in perceiving the contrastive features of a sign and articulating each parameter accurately.

As mentioned earlier, Bochner et al. (2011) found that, for sign L2 learners, location was the parameter easiest to discriminate, movement was the most difficult, and orientation and handshape fell in between these categories. This direct correspondence in perception and production for location and orientation may relate to the visual saliency and ease of execution of these parameters (because they do not require fine motor dexterity). In contrast, there is no one-toone correspondence in perception and production for the other two parameters. While handshape is more difficult to articulate than movement, in perception handshape is easier to discriminate than movement. These differences could be attributed to the physical properties of each parameter. Perception of movement 
might be difficult because of its ephemeral nature but it might be easier to articulate because it often involves movement of major limbs and proximal joints. Handshapes, in contrast, are easier to perceive because they often consist of static configurations throughout the duration of signs but require greater fine motor dexterity to be executed accurately. A tentative conclusion based on these data is that articulation errors in handshape are more likely to be related to motor dexterity while movement errors could be more linked to perception.

The different patterns of errors in production and perception tasks suggest that accurate phonemic discrimination is not the only factor responsible for learners' articulation errors. As suggested by previous work, articulation errors may derive from inaccurate perception of the sign components (Rosen, 2004) but also from inexperience in a novel motor task (Mirus et al., 2001; Rosen, 2004). The current data are also in line with research findings on L2 learning in the spoken modality. Despite some studies finding mild correlations between perception and production of novel sounds (Flege, MacKay, \& Meador, 1999), most studies have not yet been able to establish a direct link between learners' ability to perceive and produce L2 phonological contrastive features (de Jong, Hao, \& Park, 2009; Hanulikova, Dediu, Fang, Basnakova, \& Huettig, 2012; Peperkamp \& Bouchon, 2011). Our results would suggest that, despite some parameters being accurately perceived, their intrinsic articulatory complexity may lead to inaccuracies in production.

An alternative interpretation is that the errors we observed may relate to learners' oversensitivity to the relevant contrastive elements. A number of studies investigating phonological discrimination in different populations report that sign L2 learners are very attentive to phonetic detail and consider that many noncontrastive forms correspond to separate phonological categories (Best, Mathur, Miranda, \& Lillo-Martin, 2010; Hall, Ferreira, \& Mayberry, 2012; Morford, Grieve-Smith, MacFarlane, Staley, \& Waters, 2008). In contrast, the same studies have documented that deaf native signers ignore subtle phonetic differences and are more likely to collapse allophonic variants into the same category. The BSL learners in our study may have developed different phonological representations for allophonic variations of a single phoneme and as a result produced inaccurate sign forms that deviated from the model. The design of this study does not permit us to test whether inability to discriminate phonemes or oversensitivity to phonetic detail is the source of articulation errors but future studies should attempt to separate out these two factors in sign L2 learning.

The pattern of articulation errors in the current study is similar to those reported for children acquiring a sign language as L1 (Conlin et al., 2000; 
Marentette \& Mayberry, 2000; Morgan et al., 2007) and by nonsigners imitating a foreign sign language (Emmorey, Bosworth, \& Kraljic, 2009). Indeed, in spoken languages similarities between L1 and L2 phonological development have also been reported. For instance, both native and L2 learners tend to make some of the same phonemic substitutions (Flege \& Davidian, 1984) and acquire the most difficult sounds after the simpler ones have been mastered (e.g., /r/ is one of the last sounds acquired by L1 and L2 learners of Spanish; Major, 1986). It has been suggested that complexity and frequency of the target structures can explain these developmental similarities (Goldschneider \& DeKeyser, 2005; Larsen-Freeman, 1976).

Turning now to the longitudinal results of the current study, learners improved their articulation after 11 weeks ( 22 hours) of training. Improvement was significant for all phonological parameters and accuracy retained the same pattern across parameters. While instruction had an overall effect, handshape difficulty remained. However, handshape was also the parameter where instruction had the greatest impact. Perhaps the static nature of this parameter allows learners to focus more of their attention on the form of the hands than on the other parameters. The significant improvement after such a brief period of instruction indicates that, despite sign languages being expressed in the visual modality, learners develop phonological sensitivity in a similar time scale to what has been observed in spoken languages (Osterhout \& McLaughlin, 2006).

Concerning the second prediction, the increase in articulation errors as complexity increased could relate to sign structure having an impact on how learners' perceptual systems cope with contrastive manual features. Simple signs (i.e., one-handed) presented fewer components to discriminate (one handshape, one location, one movement, and one orientation) so participants' perceptual system could process the phonological components with greater ease and imitate them more accurately. In contrast, participants may not have been capable of discriminating all the phonological components of more complex signs. Two-handed signs presented two handshapes, locations, movements, and orientations (one for each hand) so this may have overloaded participants' perceptual capacities to discriminate and articulate all the contrastive features of a sign.

It is possible to see the effect of phonological complexity across different levels of a sign's internal structure. Signs articulated in signing space (Levels 1 and 3) were articulated less accurately than signs articulated on a specific body part (Levels 2 and 4). An explanation behind these unexpected results may be that proprioceptive feedback, as argued for child L1 learners (Morgan et al., 2007), might have aided articulation accuracy. It has been suggested that accurate execution of the parameters of a sign requires controlling a number of 
free parameters (degrees of freedom; Marshall, Mann, \& Morgan, 2011; Mirus et al., 2001). By holding constant one of these parameters, learners can focus their attention in order to articulate others more accurately (e.g., accuracy in place of articulation may come at the cost of low accuracy for handshape). By anchoring a sign to a specific body part and getting feedback from where it is located, participants might be able to free up resources to focus on the accurate execution of other parameters. Signs in signing space yielded lower accuracy scores perhaps because participants had to focus their attention on the correct limb movements in addition to executing the rest of the parameters accurately. It may be that mastering body-anchored locations may have a positive effect on the accurate execution of other parameters. ${ }^{3}$

In terms of number of articulators, it was found that one-handed signs (Levels 1 and 2) were articulated more accurately than two-handed signs (Levels 3 and 4). Despite two-handed signs in Levels 3 and 4 being symmetrical (dominant and nondominant hands are mirror image of each other), participants experienced more difficulties repeating them than one-handed signs. Level 6 signs were the most complex because they presented two distinct handshapes, movements, locations, and orientations and as a result were some of the least accurately articulated.

The third prediction was also confirmed. Iconic and arbitrary signs were articulated significantly differently from each other but, perhaps counterintuitively, we found that iconic signs were articulated less accurately than arbitrary signs. In addition, differences in accuracy rates were more pronounced as the number of phonological features increased. These findings suggest that iconicity may have allowed participants to have access to the meaning of the sign, but this made learners less attentive to the exact phonological structure of signs. Past research has shown that iconic signs are learned faster and more accurately than arbitrary signs by nonsigners (Baus et al., 2012; Campbell et al., 1992; Lieberth \& Gamble, 1991), meaning that novice learners do not require a signed phonological system or a manual lexicon to understand the meaning of many signs. Indeed, it has been shown for deaf signers that iconicity gives direct access to the meaning of a sign and hinders their ability to make formbased (phonological) judgements (Thompson, Vinson, \& Vigliocco, 2010). In the present study, participants may have accessed the meaning of iconic signs directly and so did not pay as much attention to their exact phonological composition because this was unnecessary. In contrast, after viewing arbitrary signs participants were unable to map them onto a referent and consequently had to pay closer attention to their constituents to imitate them accurately. Interestingly, iconic and arbitrary signs show different patterns of articulation 
accuracy across the different Complexity Levels. Iconic signs gradually decrease in accuracy as phonological complexity increases with Level 6 being the most inaccurately executed. In contrast, arbitrary signs have approximately the same values in articulation accuracy across all Complexity Levels except for signs in neutral signing space (Levels 1 and 3). These differences in articulation accuracy would suggest that the execution of the phonological constituents of iconic and arbitrary signs rely on different processing mechanisms.

An alternative explanation is that participants' gestural repertoire influenced how they executed the phonological constituents of iconic signs. ${ }^{4}$ As mentioned in previous sections, hearing adults use gestures in everyday communication and these have apparent similarities in form and meaning with many iconic signs. However, they differ in that only signs have internal organisation (i.e., gestures do not have phonology) and thus their structures are more conventionalised than gestures (McNeill, 1992). There is some evidence to suggest that at first exposure to a sign language, nonsigners produce their own gesture instead of imitating a sign with overlapping features. In a recent study, Ortega and Özyürek (2013) asked nonsigners to imitate as accurately as possible a set of BSL iconic signs. Six months later, the same participants were asked to generate a made-up sign (effectively, their gestures) for a set of English words. These words were the English translations of the iconic signs they imitated 6 months prior. The authors found that many of participants' made-up signs shared features with the conventionalised BSL signs for the same concepts. Importantly, participants were very consistent in producing the same handshapes at both points in time for many iconic depictions (see Figure 5). In some instances, this resulted in accurate sign articulations because sign and gesture had overlapping handshapes (Figures $5 \mathrm{a}$ and $5 \mathrm{~b}$ ), but in other instances it resulted in inaccurate sign articulation because they did not (Figures $5 \mathrm{c}$ and $5 \mathrm{~d})$.

Studies looking at the sources of handshape articulation errors in early signers have made similar claims before (Pichler, 2011; Ortega \& Morgan, 2010). Some studies report that adult nonsigners will not experience difficulty executing complex (marked) handshapes if these are part of their gestural repertoire. For instance, the marked handshapes or 2 will be executed accurately because these hand configurations are used in the gesture telephone and the emblem OK (Ortega \& Morgan, 2010). In contrast, nonsigners will be inaccurate at producing the unmarked handshape (i.e., with opposed thumb

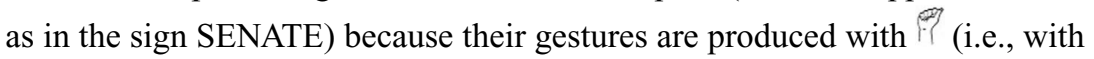
unopposed thumb; Pichler, 2011). 
Sign repetition task
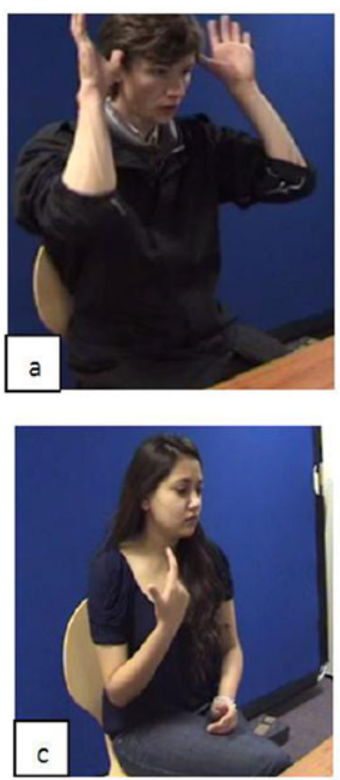

BSL sign
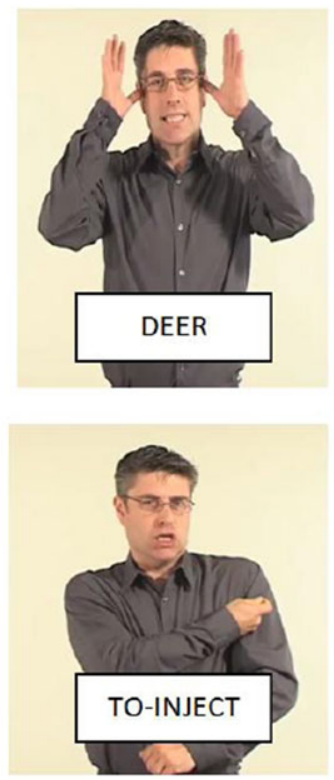

Sign generation task
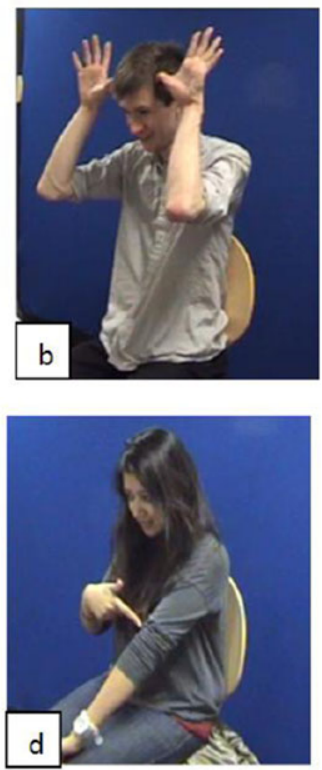

Figure 5 Gestural influence in sign articulation (Ortega \& Özyürek, 2013). Gesture will have a positive effect in sign articulation when sign and gesture have overlapping features, for example, in the handshape (Figure 5a and 5b). Gestures will have a negative effect when their structures have subtle differences with the target sign (Figure 5c and $5 d)$.

In the present study, the low articulation accuracy in iconic signs could be explained in part by signs' resemblance with co-speech gestures. Rather than imitating the exact form of iconic signs, participants may have produced their own gesture instead. Because gestures do not have the same level of conventionalisation as signs, participants' renditions deviated from the exact form of the stimulus materials. Sign articulation was accurate when sign and gesture overlapped in form, but when they did not overlap entirely it resulted in articulation errors. This interpretation is in line with earlier studies showing that nonsigners' gestures may have a positive or negative effect on sign articulation depending on their structural overlap (Pichler, 2011; Ortega \& Özyürek, 2013). It is difficult to establish the extent to which gesture affect sign production because there is no inventory of nonsigners' gestures prior to the acquisition of a sign language. However, based on the present evidence, future 
research should consider gesture as an important factor that may shape sign L2 acquisition.

In summary, sign phonological complexity and iconicity influence articulation errors at the start of sign L2 learning. Phonological development is variable across the different parameters with articulation inaccuracies being more recurrent in signs with multiple features (more phonologically complex). Accurate perception does not necessarily lead to accurate production but rather a combination of perceptual and production factors (i.e., discrimination of contrastive features and dexterity to execute them) may be a better predictor in sign L2 phonological development. Instruction has a positive effect with significant improvement being visible in all parameters, but more pronounced for handshape. Body-anchored signs are articulated more accurately than signs in neutral space possibly because proprioceptive feedback frees up learners' resources to be able to execute other parameters more accurately. Iconicity has a negative effect in articulation because learners seem to execute a manual form containing the iconic features of the sign but not its exact phonological constituents. It is possible that learners' gestural repertoire also exerts an influence in sign production but this will depend on the degree of overlap with the target sign.

The modality differences between spoken L1 and signed L2 do not allow cross-linguistic interference to happen as in unimodal (spoken-spoken) L2 phonological acquisition. However, the development of novel manual categories does not occur in a completely unbiased way either. Iconicity and learners' gestural repertoire can interfere in the accurate production of the parameters of signs. More empirical studies in cross-modal L2 acquisition are needed to delineate which factors are linked to modality and those that stem from more general properties of L2 learning.

Final revised version accepted 21 August 2014

\section{Notes}

1 Nonmanual features like eye movements, facial expressions, mouthing, and mouth gestures are also part of the sign structure (Brennan, 1992; Crasborn, van der Kooij, Waters, Woll, \& Mesch, 2008) but were not investigated in this study.

2 By convention, sign glosses are represented with the closest translation in capitals.

3 We would like to express our gratitude to one of the reviewers for insightful comments on the interpretation of these results.

4 We are indebted to the reviewers for their comments regarding the gestural influence in sign articulation. 


\section{References}

Battison, R. (1978). Lexical borrowing in American Sign Language. Silver Spring, MD: Linstok Press.

Baus, C., Carreiras, M., \& Emmorey, K. (2012). When does iconicity in sign language matter? Language and Cognitive Processes, 28, 261-271.

Best, C., Mathur, G., Miranda, K., \& Lillo-Martin, D. (2010). Effects of sign language experience on categorical perception of dynamic ASL pseudosigns. Attention, Perception, \& Psychophysics, 72, 747-762.

Best, C., \& Tyler, M. (2007). Nonnative and second-language speech perception. In O.-S. Bohn \& M. J. Munro (Eds.), Language experience in second language speech learning. In honor of James Emil Flege (pp. 13-34). Amsterdam: John Benjamins.

Bochner, J. H., Christie, K., Hauser, P. C., \& Searls, J. M. (2011). When is a difference really different? Learners' discrimination of linguistic contrasts in American Sign Language. Language Learning, 61, 1302-1327.

Boyes-Braem, P. (1990). Acquisition of the handshape in American Sign Language: A preliminary analysis. In V. Volterra \& C. J. Erting (Eds.), From gesture to language in hearing and deaf children (pp. 107-127). Washington, DC: Gallaudet University Press.

Brennan, M. (1992). The visual world of BSL: An introduction dictionary of British Sign Language/English. London: Faber \& Faber.

Brentari, D. (1999). A prosodic model of sign language phonology. Cambridge, MA: MIT Press.

Campbell, R., Martin, P., \& White, T. (1992). Forced choice recognition of sign in novice learners of British Sign Language. Applied Psycholinguistics, 13, 185-201.

Coady, J. A., \& Evans, J. L. (2008). Uses and interpretations of non-word repetition tasks in children with and without specific language impairments (SLI).

International Journal of Language and Communication Disorders/Royal College of Speech \& Language Therapists, 43(1), 1-40.

Conlin, K. E., Mirus, G. R., Mauk, C., \& Meier, R. P. (2000). The acquisition of first signs: Place, handshape, and movement. In C. Chamberlain, J. P. Morford, \& R. I. Mayberry (Eds.), Language acquisition by eye (pp. 51-70). Mahwah, NJ: Erlbaum.

Crasborn, O., vander Kooij, E., Waters, D., Woll, B., \& Mesch, J. (2008). Frequency distribution and spreading behavior of different types of mouth actions in three sign languages. Sign Language \& Linguistics, 1(1), 45-67.

Cuxac, C. (1999). French sign language: Proposition of a structural explanation by iconicity. Gesture-Based Communication in Human-Computer, 1739(1), 165-184.

deJong, K., Hao, Y.-C., \& Park, H. (2009). Evidence for featural units in the acquisition of speech production skills: Linguistic structure in foreign accent. Journal of Phonetics, 37, 357-373.

Eccarius, P., \& Brentari, D. (2007). Symmetry and dominance: A cross-linguistic study of signs and classifier constructions. Lingua, 117, 1169-1201. 
Emmorey, K., Bosworth, R., \& Kraljic, T. (2009). Visual feedback and self-monitoring of sign language. Journal of Memory and Language, 61, 398-411.

Escudero, P., \& Boersma, P. (2004). Bridging the gap between L2 speech perception research and phonological theory. Studies in Second Language Acquisition, 26, 551-585.

Flege, J. (1992). The intelligibility of English vowels spoken by British and Dutch talkers. In R. D. Kent (Ed.), Intelligibility in speech disorders: Theory, measurement, and management (pp. 157-232). Amsterdam: John Benjamins.

Flege, J. E. (1995). Second language speech learning: Theory, findings, and problems. In W. Strange (Ed.), Speech perception and linguistic experience: Issues in cross-linguistic research (pp. 233-277). Mahwah, NJ: Erlbaum.

Flege, J. E., \& Davidian, R. D. (1984). Transfer and developmental processes in adult foreign language speech production. Applied Psycholinguistics, 5, 323-347.

Flege, J. E., MacKay, I. R., \& Meador, D. (1999). Native Italian speakers' perception and production of English vowels. Journal of the Acoustical Society of America, 106, 2973-87.

Goldschneider, J. M., \& DeKeyser, R. M. (2005). Explaining the "natural order of L2 morpheme acquisition" in English: A meta-analysis of multiple determinants. Language Learning, 55(S1), 27-77.

Griffith, P. L., Robinson, J. H., \& Panagos, J. M. (1981). Perception of iconicity in American sign language by hearing and deaf subjects. Journal of Speech and Hearing Disorders, 46, 388-97.

Hall, M. L., Ferreira, V. S., \& Mayberry, R. I. (2012). Phonological similarity judgments in ASL: Evidence for maturational constraints on phonetic perception in sign. Sign Language \& Linguistics, 15, 104-127.

Hanulikova, A., Dediu, D., Fang, Z., Basnakova, J., \& Huettig, F. (2012). Individual differences in the acquisition of a complex L2 phonology: A training study. Language Learning, 62, 79-109.

Iverson, P., \& Evans, B. G. (2007). Learning English vowels with different first-language vowel systems: Perception of formant targets, formant movement, and duration. Journal of the Acoustical Society of America, 122, 2842-2854.

Johnston, T., \& Schembri, D. A. (2007). Australian Sign Language (Auslan): An introduction to sign language linguistics. Cambridge, UK: Cambridge University Press.

Kelly, S. D., Özyürek, A., \& Maris, E. (2010). Two sides of the same coin: Speech and gesture mutually interact to enhance comprehension. Psychological Science, 21, 260-267.

Kendon, A. (1995). Gestures as illocutionary and discourse structure markers in Southern Italian conversation. Journal of Pragmatics, 23, 247-279.

Kendon, A. (2004). Gesture: Visible action as utterance. Cambridge, UK: Cambridge University Press. 
Klima, E., \& Bellugi, U. (1979). The signs of language. Cambridge, MA: Harvard University Press.

Larsen-Freeman, D. E. (1976). An explanation for the morpheme acquisition order of second language learners. Language Learning, 26, 125-134.

Lausberg, H., \& Sloetjes, H. (2009). Coding gestural behavior with the NEUROGES-ELAN system. Behavior Research Methods, 41, 841-849.

Lieberth, A. K., \& Gamble, M. E. (1991). The role of iconicity in sign language learning by hearing adults. Journal of Communication Disorders, 24, 89-99.

Major, R. (1986). The ontogeny model: Evidence from L2 acquisition of Spanish r. Language Learning, 36, 453-504.

Mandel, M. A. (1977). Iconic devices in American Sign Language. In A. Friedman (Ed.), On the other hand: New pespectives on American Sign Language (pp. 57-107). New York: Academic Press.

Mann, W., Marshall, C. R., Mason, K., \& Morgan, G. (2010). The acquisition of sign language: The impact of phonetic complexity on phonology. Language Learning and Development, 6, 60-86.

Marentette, P. F., \& Mayberry, R. I. (2000). Principles for an emerging phonological system: A case study of early ASL acquisition. In C. Chamberlain, J. P. Morford, \& R. I. Mayberry (Eds.), Language acquisition by eye (pp. 71-90). Mahwah, NJ: Erlbaum.

Marshall, C. R., Mann, W., \& Morgan, G. (2011). Short-term memory in signed languages: Not just a disadvantage for serial recall. Frontiers in Psychology, 2, 1-2.

Mason, K., Rowley, K., Marshall, C. R., Atkinson, J. R., Herman, R., Woll, B., et al. (2010). Identifying specific language impairment in deaf children acquiring British Sign Language: Implications for theory and practice. British Journal of Developmental Psychology, 28, 33-49.

McNeill, D. (1992). Hand and mind: What gestures reveal about thought. Chicago: University of Chicago Press.

Meier, R. P., Mauk, C. E., Cheek, A., \& Moreland, C. J. (2008). The form of children's early signs: Iconic or motoric determinants? Language Learning and Development, 4, 63-98.

Mirus, G., Rathmann, C., \& Meier, R. P. (2001). Proximalization and distalization of sign movement in adult learners. In V. Dively, M. Metzger, S. Taub, \& A. M. Baer (Eds.), Signed languages: Discoveries from international research (pp. 103-119). Washington, DC: Gallaudet University Press.

Morford, J. P., Grieve-Smith, A. B., MacFarlane, J., Staley, J., \& Waters, G. (2008). Effects of language experience on the perception of American Sign Language. Cognition, 109, 41-53.

Morford, J. P., Wilkinson, E., Villwock, A., Piñar, P., \& Kroll, J. F. (2011). When deaf signers read English: Do written words activate their sign translations? Cognition, $118,286-292$. 
Morgan, G., Barrett-Jones, S., \& Stoneham, H. (2007). The first signs of language: Phonological development in British Sign Language. Applied Psycholinguistics, 28, $3-22$.

Newport, E. L., \& Meier, R. P. (1985). The acquisition of American Sign Language. In D. Slobin (Ed.), The cross-linguistic study of language acquisition (Vol. 1, pp. 881-938). Mahwah, NJ: Erlbaum.

Orlansky, M. D., \& Bonvillian, J. D. (1984). The role of iconicity in early sign language acquisition. Journal of Speech and Hearing Disorders, 49, 287-92.

Ortega, G., \& Morgan, G. (2010). Comparing child and adult development of a visual phonological system. Language, Interaction, and Acquisition, 1, 67-81.

Ortega, G., \& Özyürek, A. (2013). Gesture-sign interface in hearing non-signers'first exposure to sign. In Proceedings of the Tilburg Gesture Research Meeting (pp. 1-5). Tilburg, Netherlands: Tilburg University.

Ortega, G., Sümer, B., \& Özyürek, A. (2014). Type of iconicity matters: Bias for action-based signs in sign language acquisition. In P. Bello, M. Guarini, M. McShane, \& B. Scassellati (Eds.), Proceedings of the 36th Annual Meeting of the Cognitive Science Society (CogSci 2014). Austin, TX: Cognitive Science Society.

Osterhout, L., \& McLaughlin, J. (2006). Novice learners, longitudinal designs, and event-related potentials: A means for exploring the neurocognition of second language processing. Language Learning, 56(S1), 199-230.

Özyürek, A., Willems, R. M., Kita, S., \& Hagoort, P. (2007). On-line integration of semantic information from speech and gesture: Insights from event-related brain potentials. Journal of Cognitive Neuroscience, 19, 605-616.

Peperkamp, S., \& Bouchon, C. (2011). The relation between perception and production in L2 phonological processing. Interspeech, 2011, 161-164.

Perniss, P., Thompson, R. L., \& Vigliocco, G. (2010). Iconicity as a general property of language: Evidence from spoken and signed languages. Frontiers in Psychology, 1, 1664-1678.

Pichler, D. C. (2011). Sources of handshape error in first-time signers of ASL. In G. Mathur \& D. J. Napoli (Eds.), Deaf around the world: The impact of language (pp. 96-126). Oxford, UK: Oxford University Press.

Piske, T., MacKay, I., \& Flege, J. (2001). Factors affecting degree of foreign accent in an L2: A review. Journal of Phonetics, 29, 191-215.

Pizzuto, E., \& Volterra, V. (2000). Iconicity and transparency in Sign Languages: A cross-linguistic cross-cultural view. In K. Emmorey \& H. L. Lane (Eds.), The signs of language revisited: An anthology to honor Ursula Bellugi and Edward Klima (pp. 229-250). Mahwah, NJ: Erlbaum.

Rosen, R. S. (2004). Beginning L2 production errors in ASL lexical phonology: A cognitive phonology model. Sign Language and Linguistics, 7, 31-61.

Sandler, W., \& Lillo-Martin, D. (2006). Sign language and linguistic universals. Cambridge, UK: Cambridge University Press. 
Shook, A., \& Marian, V. (2012). Bimodal bilinguals co-activate both languages during spoken comprehension. Cognition, 124, 314-324.

Stokoe, W. (1960). Sign language structure: An outline of the visual communication systems of the American deaf (Studies in linguistics: Occasional papers, Paper 8). Buffalo, NY: University of Buffalo.

Suter, R. (1976). Predictors of pronunciation accuracy in second language learning. Language Learning, 26, 233-253.

Sutton-Spence, R., \& Woll, B. (1999). The linguistics of British Sign Language: An introduction. Cambridge, UK: Cambridge University Press.

Taub, S. (2001). Language from the body: Iconicity and metaphor in American Sign Language. Cambridge, UK: Cambridge University Press.

Thompson, R. L., Vinson, D. P., \& Vigliocco, G. (2009). The link between form and meaning in American Sign Language: Lexical processing effects. Journal of Experimental Psychology. Learning, Memory, and Cognition, 35, 550-557.

Thompson, R. L., Vinson, D. P., \& Vigliocco, G. (2010). The link between form and meaning in British sign language: Effects of iconicity for phonological decisions. Journal of Experimental Psychology. Learning, Memory, and Cognition, 36, 1017-1027.

Thompson, R. L., Vinson, D. P., Woll, B., \& Vigliocco, G. (2013). The road to language learning is iconic: Evidence from British Sign Language. Psychological Science, 23, 1443-1448.

Vander Kooij, E. (2002). Phonological categories in sign language of the Netherlands: The role of phonetic implementation and iconicity. Utrecht, Netherlands: LOT.

Vinson, D. P., Cormier, K., Denmark, T., Schembri, A., \& Vigliocco, G. (2008). The British Sign Language (BSL) norms for age of acquisition, familiarity, and iconicity. Behavior Research Methods, 40, 1079-1087.

\section{Supporting Information}

Additional Supporting Information may be found in the online version of this article at the publisher's website:

Appendix S1: Phonological Information of the Signed Stimuli in the Arbitrary and Iconic Condition.

Appendix S2: List of Arbitrary and Iconic Signs with their Phonological Properties and Iconicity Ratings.

Appendix S3: All Possible Comparisons between the Different Articulation Accuracies for Each Complexity Level. 